\title{
LAS CIUDADES PATRIMONIALES CUBANAS COMO PRODUCTO TURÍSTICO
}

\author{
Gabino Ponce Herrero \\ Departamento de Geografía Humana \\ Universidad de Alicante
}

\section{RESUMEN}

Del análisis de las demandas se comprueba el predominio del producto turístico de sol y playa en Cuba. No obstante, la especialización y diferenciación tanto del producto turístico como de la oferta complementaria son la clave para acceder a mayores segmentos del mercado turístico, y, al tiempo, para evitar la creciente competencia de otros destinos próximos que, si bien plantean una seria competencia en cuanto a los productos de sol y la playa, se manifiestan como destinos cultural y patrimonialmente vacíos. La evolución futura de la demanda turística hacia Cuba refuerza el interés creciente por los recursos patrimoniales. Así, las ciudades patrimoniales cubanas deben poner en marcha y/o seguir desarrollando estrategias que potencien las prácticas turísticas asociadas a la cultura y al patrimonio, que tienen la ciudad como soporte esencial. Pero tales procesos de cualificación del producto turístico urbano deben realizarse sobre la base de la integración de los procesos en la mejora general de la calidad de vida de los ciudadanos (más infraestructuras y equipamientos) y de la mejora concreta de los escenarios - de vida cotidiana y para el turismo-, siempre bajo criterios de mantener la autenticidad y no alterar, en lo posible, los modos de vida convertidos en producto turístico.

Palabras clave: turismo, patrimonio, cultura, equipamientos urbanos, desarrollo integrado.

\section{ABSTRACT}

Demand analysis has confirmed the predominance of sun, sea and sand tourism in Cuba. Nevertheless, specialisation and differentiation of both the tourist 
product and the complementary offer are key to reaching larger segments of the tourism market. At the same time, Cuba must fight off increasing competition from other nearby destinations which may put up serious competition in terms of sun, sea and sand products but which prove woefully lacking in terms of culture and heritage. The future evolution of tourist demand for Cuba reinforces the growing interest in its patrimonial resources. Thus, Cuba's ancestral towns and cities must implement and/or continue to develop strategies to promote tourism practices relating to culture and heritage, in which the city is the main arena. Nevertheless, the processes involved in qualifying urban spaces as tourism products must be based on integrating such processes into the general improvement of citizens' quality of life (more infrastructures and facilities) and the specific improvement of sites and spaces - everyday spaces as well as tourist spaces, whilst maintaining authenticity and, as far as possible, preserving the customs that have been turned into tourist products.

Key words: tourism, heritage, culture, urban facilities, integrated development.

\section{RÉSUMÉ}

Lanalyse de la demande fait apparaître la prédominance d'un produit touristique de type soleil et plage à Cuba. Cependant, la spécialisation et la différentiation, aussi bien du produit touristique que de l'offre complémentaire, sont la clef pour accéder à des segments plus amples dans le marché du tourisme tout en évitant la concurrence croissante d'autres destinations voisines. Cellesci représentent une concurrence sérieuse en ce qui concerne les produits soleil-plage, mais du point de vue de la culture et du patrimoine c'est le vide. Lévolution future de la demande touristique sur Cuba doit donc tirer parti de l'intérêt croissant pour les ressources du patrimoine culturel. Ainsi, les villes cubaines dotées de patrimoine doivent mettre en marche et/ou continuer de développer des stratégies visant à favoriser les pratiques touristiques liées à la culture et au patrimoine, dont le milieu urbain est le support essentiel. Mais de tels processus de qualification du produit touristique urbain doivent être réalisés sur la base de l'intégration des processus dans l'amélioration générale de la qualité de vie des citadins (plus d'infrastructures et d'équipements), et dans l'amélioration concrète des espaces (de la vie quotidienne et pour le tourisme). Et ce en suivant des critères constants visant à maintenir l'authenticité et à ne pas altérer, dans la mesure du possible, les modes de vie transformés en un produit touristique.

Mots clés: tourisme, patrimoine, culture, équipements urbains, développement intégré. 
La peculiar historia de la Isla de Cuba, puente en el descubrimiento y la conquista de toda América, eje del comercio con la Metrópolis, emporio azucarero y nodo intercambiador de conocimiento a lo largo de cinco siglos, explican la riqueza patrimonial del País, entre la que sobresale el rico y variado acervo urbanístico y arquitectónico, a veces mantenido en el tiempo por la afección de severas crisis que interrumpieron su renovación. Así, en Cuba se halla un gigantesco compendio de elementos y conjuntos arquitectónicos de los más diversos estilos, que conviven armoniosamente en espacios de abigarrado eclecticismo. En cada ingenio, poblado o ciudad es posible identificar piezas singulares de arquitectura.

La Comisión Nacional de Monumentos de Cuba tiene declarados 230 Monumentos Nacionales y 189 Monumentos Locales, bajo el criterio de constituir un centro histórico urbano, una construcción o un sitio que, por su carácter excepcional, cuenta con una notable significación cultural, histórica o social para el País o para la ciudad en cuestión. En la relación de centros históricos con categoría de Monumento Nacional se hallan los de Remedios, Sancti Spiritus, Sta. María del Puerto Príncipe, Gibara, Birán, Bayamo y Santiago de Cuba. Además, otros conjuntos patrimoniales han alcanzado la categoría de Patrimonio de la Humanidad.

Cuadro 1. Síntesis Patrimonio Cultural Cuba. Principales lugares

\begin{tabular}{|l|l|l|l|}
\hline \multicolumn{1}{|c|}{$\begin{array}{c}\text { Red de primeras Villas } \\
\text { (fundacionales) }\end{array}$} & $\begin{array}{c}\text { Red Oficinas } \\
\text { del Historiador/ } \\
\text { Conservador de la } \\
\text { ciudad }\end{array}$ & Patrimonio Humanidad & \multicolumn{1}{|c|}{ Características } \\
\hline $\begin{array}{l}\text { Nuestra Señora de la Asunción de } \\
\text { Baracoa (1511) }\end{array}$ & \multicolumn{1}{|c|}{\begin{tabular}{l} 
Trinidad (1997) \\
\hline San Salvador de Bayamo (1513)
\end{tabular}} & $\begin{array}{l}\text { centro histórico y Valle de } \\
\text { los Ingenios (1988) BC }\end{array}$ & $\begin{array}{l}\text { arquitectura colonial/ } \\
\text { paisaje agrícola }\end{array}$ \\
\hline Santísima Trinidad (1514) & Camagüey (1999) & $\begin{array}{l}\text { centro histórico (2008) } \\
\text { BC }\end{array}$ & arquitectura colonial \\
\hline Sancti Spiritu (1514) & Santiago (1996) & $\begin{array}{l}\text { Castillo San Pedro de la } \\
\text { Roca (1997) }\end{array}$ & sistema fortificaciones \\
\hline $\begin{array}{l}\text { Sta. María del Puerto del Príncipe colonial } \\
\text { (1514)/ Camagüey (1576) }\end{array}$ & La Habana (1938) & $\begin{array}{l}\text { centro histórico y } \\
\text { fortificaciones (1982) BC }\end{array}$ & $\begin{array}{l}\text { barroco, neoclásico, } \\
\text { fortificaciones }\end{array}$ \\
\hline Santiago de Cuba (1515) & Cienfuegos (2008) & $\begin{array}{l}\text { centro histórico (2005) } \\
\text { BC }\end{array}$ & $\begin{array}{l}\text { plano y arquitectura } \\
\text { neoclásica }\end{array}$ \\
\hline $\begin{array}{l}\text { San Cristóbal de } \\
\text { La Habana (1519) }\end{array}$ & $\begin{array}{l}\text { Valle de Viñales (1999) } \\
\text { BC }\end{array}$ & $\begin{array}{l}\text { paisaje agrícola/ } \\
\text { naturaleza }\end{array}$ \\
\hline & $\begin{array}{l}\text { paisaje arqueológico } \\
\text { cafetales (2000) BC }\end{array}$ & restos cafetales \\
\hline BC: bien cultural; BN: bien natural; BI: bien inmaterial; (año de fundación o declaración) \\
\hline
\end{tabular}

Fuente: UNESCO, Red Oficinas del Historiador y el Conservador, 2010 
Desde los años 90, prácticamente todas las ciudades cubanas han desarrollado, en mayor o menor medida, estrategias de recuperación de su patrimonio urbano para su puesta en valor de cara a la creciente demanda turística de ese tipo de productos. Muy destacada ha sido la labor desarrollada en La Habana Vieja, modelo de gestión internacional y, también, nacional, al que siguen otras ciudades cubanas que han puesto en funcionamiento Oficinas del Historiador o del Conservador, siguiendo la estela de la de La Habana. Al tiempo, en 1994 se creaba el Ministerio de Turismo (MINTUR) para administrar los recursos turísticos y desarrollar estrategias para la comercialización más eficiente del producto turístico elaborado en el País, entablándose, desde entonces, una estrecha complementariedad entre la recuperación del patrimonio y su puesta en valor, no exenta de discusión, que ha posibilitado, empero, notables niveles de desarrollo económico.

\section{PATRIMONIO Y TURISMO EN EL CONTEXTO URBANO}

El turismo constituye uno de los motores de la economía en las sociedades desarrolladas postindustriales, y también de las economías emergentes preindustriales, como es el caso de Cuba, tanto por su contribución a la generación de riqueza y empleo como por su importante efecto de arrastre sobre los otros sectores económicos, lo que le confiere un carácter estratégico de primera magnitud. En general, las estrategias de diversificación y producción de nuevos productos y destinos turísticos han puesto de manifiesto la importancia de la cultura como factor de atractivo y clave para la formalización de esos nuevos productos.

Dentro de ese concepto general, algunos autores consideran dos categorías: el turismo urbano y el turismo cultural propiamente dicho. El primer concepto incluye necesariamente al segundo, aunque es más amplio. Por su parte, el turismo cultural presenta una variada gama de tipologías, muchas de ellas ya en curso en las ciudades patrimoniales cubanas o con grandes posibilidades de desarrollo.

El turismo urbano, en general, ha experimentado un elevado índice de crecimiento en las últimas décadas, favorecido por dinámicas convergentes, como son la puesta en valor de muchos centros históricos, pero también por la ampliación y diversificación de las prácticas culturales (gastronomía, música, etc.), el interés que demuestran los consumidores por el patrimonio y el urbanismo, la búsqueda de actividades y las posibilidades de hacer compras. Sin duda, para este tipo de producto turístico ha resultado fundamental el fraccionamiento de las vacaciones, y la mejora constante de las posibilidades de movilidad de las personas. 
No han escapado a los gestores públicos cubanos las potentes dinámicas de esas tendencias, de forma que, en general, todos coinciden en fomentar el turismo como eje de desarrollo económico, creador de riqueza y de empleo. Pero también como eje estratégico de una política de ordenación urbana, que, a la vez que mejore las condiciones de vida de los ciudadanos y cumpla con todas sus exigencias, genere una oferta turística competitiva destinada a satisfacer las expectativas de los visitantes, con el objetivo último de convertirse en un nuevo motor para el desarrollo armónico y equilibrado de la ciudad y del bienestar de sus habitantes.

La Organización Mundial del Turismo considera que casi un 40\% de los viajes mundiales tienen una motivación cultural. Por su parte, la Carta de Turismo Cultural del ICOMOS (1976) define el turismo cultural como:

aquella forma de turismo que tiene por objeto, entre otros fines, el conocimiento de monumentos y sitios histórico-artísticos. Ejerce un efecto realmente positivo sobre éstos en tanto en cuanto contribuye -para satisfacer sus propios fines- a su mantenimiento y protección. Esta forma de turismo justifica, de hecho, los esfuerzos que tal mantenimiento y protección exigen de la comunidad humana, debido a los beneficios socio-culturales y económicos que comporta para toda la población implicada.

El turismo cultural se practica, sobre todo, en los núcleos urbanos que cuentan con un elevado número de recursos patrimoniales, que pueden compaginarse con otras ofertas como el turismo de sol y playa y, además, contribuir a su cualificación y diferenciación. Para el caso de las ciudades patrimoniales cubanas cabe señalar las potencialidades inherentes al turismo de negocios, de congresos, idiomático o residencial (compartir vivienda con familias cubanas).

\section{LA OFERTA CULTURAL POTENCIAL DE LOS NÚCLEOS URBANOS}

Para afinar las propuestas de las ciudades patrimoniales cubanas en proceso de conversión en productos turísticos, es preciso identificar los componentes variados que se integran dentro de la definición de «turismo cultural» y que pueden ser clave en las apuestas de futuro de esas ciudades. Dentro del paraguas de turismo cultural aparecen los segmentos específicos de:

- turismo patrimonial, que, en las ciudades cubanas, adquiere la doble vertiente de:

- patrimonio tangible: arqueológico, urbanístico, arquitectónico.

- patrimonio intangible: cultura, fiestas y celebraciones tradicionales.

- turismo literario, también con varias facetas:

- la ciudad como escenario de ficción: la ciudad relatada en obras literarias atrae a visitantes, fundamental resulta la obra La ciudad de las 
columnas, de Alejo Carpentier, pero también otras muchas obras literarias con el trasfondo de La Habana ${ }^{1}$, aunque menguan las referencias literarias que han alcanzado difusión para las demás ciudades patrimoniales.

- premios y eventos literarios: la ciudad organiza el Día o la Feria del Libro, o diversos premios (de poesía, de novela...), como el Premio Literario Casa de las Américas, el Concurso Literario Alfredo Torroella, o el Concurso Literario Casa de Hierro, celebrados en La Habana y, en algunas ediciones, en otras ciudades patrimoniales, como en Cienfuegos o en Las Tunas (Tunarte).

- turismo de festivales: se trata de uno de los productos más extendidos entre las ciudades patrimoniales cubanas; prácticamente en todas ellas se celebran algún tipo de festivales con vocación de internacionalidad, hasta el punto de que ha sido producto bien identificado y competitivo en el Mundo, gestionado, entre otras, por empresas muy especializadas en eventos de festivales, como la empresa Excelencias Travel (la web especializada www.congressesincuba.com recoge y publicita la diversa y variada ofertas al respecto, prácticamente extendida por todo el País).

- turismo musical: Actuaciones de calidad que atraigan visitantes desde otras ciudades (los macro conciertos reivindicativos como oportunidad).

- turismo de raíces o genealógico: la ciudad emisora de emigrantes atrae a sus descendientes; se trata de un notable segmento turístico, condicionado, no obstante, por las dificultades del viaje para los cubanos afincados en los EE.UU.

- turismo étnico o etnoturismo: se trata de una de las modalidades de turismo más interesantes para las ciudades cubanas, ya que genera un gran atractivo entre las personas aficionadas por la cultura afrocubana, el sincretismo y la santería; el objetivo consiste en vincular ese tipo de turismo con excursiones integradas, para superar el localismo -o el culto muy concreto que se manifiesta como producto acotado y de escasa relevancia para el resto de la ciudad-y ofertar la cultura y las costumbres de las personas que habitan en el conjunto de la ciudad donde se dan esas manifestaciones culturales.

1 Ejemplos han sido tratados en diferentes congresos, como «El mulato en ciudad de La Habana del siglo XIX en Cecilia Valdés y Sab», por María Espinoza, Florida International University; "La ciudad de La Habana para un infante difunto: espacio modificador y modificado», por María Milán, Borough of Manhattan Community College, o «Hacia una estética posmoderna de la ruina: Antonio José Ponte y La Habana», por Gerardo Muñoz, University of Florida. 
- turismo gastronómico: no se halla muy elaborado en Cuba; por el contrario, la gastronomía no deja de ser un mero producto complementario, no siempre bien integrado en el producto; las ciudades pueden favorecerse de la mixtura de las cocinas europeas y africanas como elemento diferenciador.

- turismo religioso: tampoco aparece como producto bien definido en el contexto cubano, donde sólo destacan las peregrinaciones -sobre todo de componente interna- hacia la Virgen del Cobre; otra cosa es el ya comentado atractivo que genera el sincretismo y la santería, con verdadera capacidad de captar turistas específicos desde el extranjero.

- turismo científico: la ciudad como plataforma para la celebración de congresos, jornadas y reuniones científicas es producto muy explotado por La Habana, que se ha situado en posición muy competitiva en el mercado global, tanto por sus atractivos como, sobre todo, por sus ventajas en las comunicaciones nacionales e internacionales, con las que difícilmente pueden competir otras ciudades patrimoniales cubanas.

- turismo idiomático: la ciudad como escuela de español es producto por desarrollar en las ciudades patrimoniales cubanas.

- turismo creativo: tanto para fotografías, como para pintura, literatura y música, pero también para otras actividades más vinculadas con la ciencia, como puede ser, en el caso cubano, la informática y el desarrollo de software.

Las principales ciudades patrimoniales cubanas -sobre todo La Habana y, en menor medida, Santiago, Cienfuegos o Trinidad- ya llevan andado un buen camino en algunas de estas categorías, mientras en otras se hallan en fase incipiente, bien que sólo mediante el desarrollo parcial del conjunto de propuestas señaladas. Se trata de productos con características específicas, que exigen también estrategias selectivas de gestión, promoción y comercialización, lo que constituye uno de los principales retos de la enorme complejidad inherente al turismo cultural.

En el caso de Cuba, el espacio geográfico es doblemente condicionante, ya que el turismo cultural puede desarrollarse combinando destinos urbanos con otros destinos rurales, litorales o de montaña próximos. La ciudad ejerce de polo central -principal atractivo-, donde se concentra toda o la mayor parte de la oferta complementaria: base de excursiones. La mejora de la conectividad con el resto del territorio más allá de la propia ciudad patrimonial sugiere unas enormes posibilidades como, por ejemplo, el turismo de aventura y el turismo de experiencia como complemento y valor diferenciador del producto turístico cultural o urbano: el Escambray como base para la aventura desde Trinidad, el Turquino desde Santiago o la Sierra de los Órganos desde Pinar del Río, donde, de hecho, ya se da esa simbiosis entre turismo cultural y de naturaleza, bien que con un marcado carácter de excursionismo y/o de estancias muy breves. 


\section{HACIA UN DIAGNÓSTICO RACIONAL DE LAS POTENCIALIDADES}

Objetivo esencial debe ser que el turismo se erija no sólo en herramienta de desarrollo socioeconómico, sino también, o de manera especial, en instrumento para la recuperación y conservación del patrimonio. Las estrategias locales de las ciudades patrimoniales deben ir orientadas hacia un equilibrio armónico entre conservación del patrimonio, convivencia ciudadana y presencia turística. Para ello, la puesta en valor como destinos para el turismo cultural debe ser fruto de un diagnóstico fino, donde se conjuguen en forma y tiempo las posibilidades generales, las tipologías posibles y las necesidades de la sociedad local.

Por otro lado, no basta con tener un rico potencial patrimonial para generar un turismo cultural rentable. El turismo es un negocio frágil en el que intervienen otros aspectos mercantilistas, como los que se exponen:

- Un proyecto sostenible debe ajustarse a la capacidad de carga del destino -de cada una de las ciudades- dejando de lado hipótesis excesivas de potencialidades o de demanda. Debe tener en cuenta la conservación permanente de los recursos, la disminución de los costes de intervención y ajustar las obligaciones de la puesta en valor a las posibilidades de financiación real (pública y privada).

- De igual manera, un proyecto sostenible debe integrarse con el resto del territorio: la singularidad del patrimonio no es suficiente para superar problemas de aislamiento geográfico, ni para resolver los problemas económicos de una ciudad. Resulta fundamental la integración del turismo cultural con las demás estrategias de desarrollo socioeconómico de la ciudad, como una más de las alternativas, pero no como la única alternativa.

- Debe considerarse que el turismo cultural no se orienta sólo a captar turistas de lejanas procedencias; por el contrario, es muy factible el desarrollo de estrategias encaminadas a captar turistas y visitantes alojados en ciudades vecinas, que se ajustan en todas las consideraciones al perfil del turista urbano -breves estancias, consumo de oferta complementaria (compras, gastronomía, eventos, teatros, etc.)-, segmento que puede llegar a tener un peso singular en las estrategias concretas de cada ciudad patrimonial. De ese modo, los grandes equipamientos -necesarios- deberán conjugarse adecuadamente con proyectos de pequeña escala, menos impresionantes, pero igualmente rentables, y a menudo más asequibles a la gestión local, ya que se fundamentan en los recursos locales realmente movilizables (finanzas, pequeñas empresas locales y redes locales de empresas con circuitos temáticos), y sus posibilidades de integración con las demás actividades existentes. 
- En sentido contrario, proyectos demasiado ambiciosos o poco ajustado a las posibilidades reales demandarán elevados presupuestos para su concreción y para su posterior mantenimiento, sin que la frecuentación turística esperada sea suficiente para su rentabilización.

- En cada ciudad patrimonial, resulta preciso evaluar los niveles de frecuentación desde su territorio más inmediato y desde los puntos de llegada de turistas al País - por lo general, el aeropuerto de La Habana-, para identificar su verdadera jerarquía urbana y su papel como nodo de servicios administrativo, económico y de servicios generales y específcos en ese ámbito de influencia.

Como premisas imprescindibles para la puesta en valor el patrimonio cultural, aparecen destacados algunos de los consejos de la Organización Mundial del Turismo²:

- Coordinación de todos los actores locales, incluyendo a los colectivos más vulnerables, bajo la tutela de la administración local, que ha de velar por el correcto y equilibrado desarrollo, mediante proyectos, disposiciones legales o diversos incentivos, dirigiendo las reglas del juego para que las oportunidades lleguen a todas las empresas y agentes locales.

- El turismo cultural se fundamenta en la «autenticidad» de la oferta, y en el conocimiento de otras culturas, más que en las condiciones climáticas (que, en el caso de Cuba, también acompañan). Por ello, no debe enfatizarse en la tematización estereotipada de la oferta. Con frecuencia, en algunos destinos culturales y etnoculturales la vida real se esconde detrás de una representación ficticia, en un proceso de «artificialización» del lugar, que acaba vacío de vida real y carente de verdadero interés cultural.

- Es importante que asuman responsabilidades tanto el sector público como el sector privado, los profesionales del patrimonio, los profesionales de la oferta complementaria (hotelería, gastronomía, ocio, etc.) y los vecinos.

- Debe atender, sobre todo, a la capacidad de movilización de los recursos locales, más comprometidos con la eficacia y sostenibilidad del destino turístico concreto. Tales inversiones locales son más seguras y responden a las capacidades reales de desarrollo.

En ese sentido, deben ser citadas de manera expresa las recomendaciones que en 2008 hacía en La Habana Herman van Hoof, director de la Oficina Regional de Cultura para América Latina y el Caribe de la UNESCO, sobre las políticas de gestión de los centros históricos ${ }^{3}$, al proponer el modelo de las cuatro c:

2 www.world-tourism.org WTO (OTM).

3 www.opushabana.cu VII Encuentro Internacional sobre Manejo y Gestión de Centros Históricos, La Habana Vieja, 2008. 
- Credibilidad, o la capacidad de identificar, valorar y potenciar los valores patrimoniales de la ciudad;

- Conservación, sembrar conciencia del compromiso tanto por parte del Estado como de la población en la salvaguarda de ese patrimonio;

- creación de capacidades, lograr una infraestructura equilibrada de entidades que garanticen la habitabilidad y la calidad de vida a los habitantes, en funciones tales como: generación de empleos, red de servicios, consolidación de las estructuras arquitectónicas de los inmuebles y capacidades de disfrute cultural;

- Comunicación, fomentar encuentros, eventos, debates y publicaciones que den a conocer los resultados de las acciones emprendidas en la defensa del patrimonio a la vez que generen nuevas soluciones.

\subsection{La oferta patrimonial}

Los encargados de velar por el patrimonio cubano son el Consejo Nacional del Patrimonio Cultural y las Comisiones Nacionales y Provinciales de Monumentos. No obstante, en algunas de las ciudades patrimoniales cubanas se han desarrollado oficinas de conservación que toman como ejemplo la Oficina del Historiador de La Habana Vieja. La lista es reducida: Oficina del Historiador de Baracoa, Oficina del Conservador de Trinidad y del Valle de los Ingenios, Oficina del Conservador de Camagüey, Oficina del Conservador de Santiago de Cuba y Oficina del Conservador de Cienfuegos. Se trata de la mayor parte de las ciudades de la red Primeras Villas (salvo Bayamo y Sancti Spiritus), más la ciudad de Cienfuegos, cuyo plano fundacional -y por extensión el centro histórico- fue declarado Patrimonio Cultural de la Humanidad en 2005.

Por lo general -salvo el caso específico de La Habana Vieja, que goza de una mayor autonomía y desarrolla gran profusión de programas de todo tipo, que trascienden los límites de La Habana Vieja ${ }^{4}$-, esas oficinas de conservación se hallan subordinadas a los Consejos de la Administración Municipal, y constituyen entidades jurídicas con facultad suficiente para:

- Preservar la memoria material y espiritual de la ciudad como expresión de la historia nacional;

- Formular, materializar y hacer cumplir los objetivos, estrategias, política y los planes dirigidos a la conservación, preservación cultural, arquitectónico y espiritual del Centro Histórico;

4 Oficina del Historiador de La Habana: www.habananuestra.cu

5 Oficina del Conservador de Trinidad y del Valle de los Ingenios: www.fenix.co.cu/villa/ Vtoficina.htm 
- Fiscalizar las actividades que con relación a los bienes que integran la zona priorizada para la conservación llevan a cabo otras entidades no subordinadas a la Oficina del Conservador;

- Formalizar convenios con los organismos y entidades situadas en la zona priorizada para la conservación;

- Recibir y utilizar donaciones.

En esas ciudades, tarea fundamental ha sido la realización de inventarios de edificios patrimoniales para proceder a su restauración, mantenimiento y conversión ineludible en producto turístico: hoteles, restaurantes, museos, galerías de arte, centros culturales; en un proceso que ha reforzado su poder de atracción hacia el lugar central, si bien a costa de transformar su realidad socioeconómica para recrear los viejos escenarios coloniales, incluso con figurantes vestidos a la antigua usanza. Sin embargo, en el resto de las ciudades cubanas con valor patrimonial, buena parte de la gestión se circunscribe a la administración ordinaria del centro histórico, identificado más como otro barrio de la ciudad que como lugar concreto donde se atesoran los valores culturales (aunque existe una nueva sensibilidad plasmada en algunas nuevas directrices urbanísticas).

El turismo cultural no sólo consume centro histórico. De hecho, es un turismo básicamente urbano que consume ciudad en toda su integridad. Por ello, las estrategias acantonadas en uno solo de los barrios de la ciudad, además de desequilibrantes, pueden no llegar a ser del todo eficaces.

En ese sentido, cabe destacar el peso que, en el desarrollo del producto turístico, tienen los servicios y equipamientos considerados como complementarios, por lo general dispersos por el resto de la ciudad. En España, el grupo de investigación Turismo y Ciudades Históricas (De la Calle, 2002) ha desarrollado una metodología que considera a la ciudad como el negocio turístico integral, y no sólo al centro histórico. Aplicada al caso de la ciudad de Toledo, el grupo identificaba un inventario de actividades relacionadas con el turismo, bien en el centro histórico, bien en el resto de la ciudad, conforme con la naturaleza del producto ofertado (actividades turísticas primarias o complementarias), o de la ubicación del establecimiento (actividades turísticas directas o indirectas). Con esos criterios, la ciudad se clasificó en una serie de espacios funcionales, claramente aplicables a las ciudades patrimoniales cubanas para su adecuada planificación:

- Eje o foco turístico principal, que se corresponde con el centro histórico por naturaleza, siguiendo las rutas o sendas más concurridas por los turistas, guiados y por libre. En el caso cubano, en ese ámbito se da una gran concentración de establecimientos orientados a la oferta directa, como restaurantes, casas de hospedaje, galerías y museos, pero menu- 
dean los grandes alojamientos hoteleros que, por lo general, o no existen, o están ubicados en las afueras, junto a algún recurso de naturaleza, preferentemente las playas (caso de la Península de Ancón en Trinidad) o de la montaña.

- Área turística secundaria, definida por las calles que circundan el foco principal, donde decae la densidad de actividades turísticas primarias, ya que los turistas tan sólo las recorren de manera ocasional. Es el espacio donde una potente oferta urbana de servicios no turísticos -comercio general, tiendas de alimentación, bares y restaurantes, bancos, agencias profesionales, servicios médicos, etc.- potencia el atractivo de la ciudad histórica y, en realidad, sustenta el negocio turístico concebido de manera integral. Se trata de las denominadas actividades turísticas indirectas, que, en las ciudades patrimoniales cubanas, se halla por desarrollar aprovechando el tirón del centro histórico (o resultan insuficientes incluso para la propia ciudadanía). En estas ciudades, este espacio urbano que envuelve al centro histórico es el lugar donde proliferan las casas de hospedaje y los servicios para la ciudadanía en general, como bares, tiendas y algunos servicios personales, como barberías y otros, de manera que, a la par que descienden los turistas, aumentan los transeúntes locales.

- Centro histórico no turístico, ámbitos del centro histórico no afectados por los recorridos turísticos, bien por su menor calidad ambiental, bien por no haber sido afectados todavía por el fenómeno de puesta en valor del recinto histórico. Son espacios de vida normal, donde pululan las familias, bien que afectados por la insuficiencia de los servicios y equipamientos existentes (los que existen están todos orientados hacia el turismo). Se trata de espacios aquejados por los problemas característicos de los barrios envejecidos, donde las carencias y el deterioro físico se van generalizando, mientras las nuevas viviendas y los equipamientos sociales se levantan en los desarrollos periféricos. Merecen una mayor atención para salir, de manera conveniente, del estado de letargo o deterioro en que se hallan.

- Núcleos turísticos periféricos, identificados como espacios fuera del recinto histórico, sin valor patrimonial, pero que concentran gran cantidad de visitantes, como es el caso de las estaciones de autobuses, o las calles que llevan a los grandes hoteles periféricos.

- Resto de la ciudad, que da soporte al negocio turístico por medio de las relaciones intersectoriales que satisfacen las demandas turísticas específicas de bienes y servicios y de mano de obra. La demanda turística 
beneficia al conjunto de la ciudad -desde los agricultores y pescadores que proporcionan alimentos, hasta los servicios médicos y asistenciales que mantienen a la población activa, pasando por las oficinas de la Administración local y estatal-. Se trata de actividades turísticas intermedias $o$ inducidas que, en la práctica, se extienden al conjunto del entramado productivo local. Resultan fundamentales, ya que son el soporte de la vida cotidiana de la ciudad y merecen tanto esfuerzo como el destinado al foco turístico principal.

\subsection{La oferta etnográfica}

Se trata de un conjunto de actividades sociales, religiosas y étnicas vinculadas a la cultura popular, que, individualmente o de forma colectiva, pueden constituir un destacado atractivo para las ciudades patrimoniales. Complementan la oferta cultural museística y se diferencian claramente de ella, dado que se trata de expresiones de una cultura viva, rica y variada, como es la «cultura criolla» o la «cultura afrocubana», con todas sus manifestaciones religiosas y populares: cristianismo, sincretismo, santería, carnaval, etc., pero también la zafra, la cosecha, la matanza y otras actividades propias del ciclo agrícola o pesquero anual.

Estas manifestaciones de la cultura popular, por ser muy sentidas por los propios cubanos -autenticidad-, gozan de una elevada consideración en la apreciación de los turistas, y son por sí motivos suficientes de atracción. No obstante, como va dicho, se corre el riesgo de la tematización y, por ello, de la falsificación de las representaciones, que dejan de ser expresiones del sentir popular y acaban convertidas en otro producto turístico más.

El calendario anual de tales festividades y eventos permite un interesante reparto a lo largo de las estaciones, de forma que su puesta en valor puede contribuir a desestacionalizar la oferta y, también, a captar turistas para estancias breves, de fin de semana -desde otros destinos cubanos- o de varios días, mientras dura la festividad.

\subsection{La oferta hotelera}

La oferta de alojamientos en Cuba ha ido aumentando en cantidad y en calidad, de forma que, al tiempo que aumentaban las plazas hoteleras en establecimientos de 4 y 5 estrellas, han descendido o se han mantenido prácticamente en los mismos niveles las plazas en hoteles de menor categoría. De igual modo, la oferta hotelera se ha ido extendiendo por todas las provincias del País, en especial allí donde las playas y el paisaje han permitido poner en valor nuevos productos de sol y playa. 
Cuadro 2. Cuba. Oferta de plazas-camas según tipología del establecimiento

\begin{tabular}{|l|c|c|c|c|c|c|}
\hline \multicolumn{1}{|c|}{ Número de plazas-cama } & 2003 & 2004 & 2005 & 2006 & 2007 & 2008 \\
\hline Hoteles y otros establecimientos & 84.200 & 85.605 & 87.252 & 89.302 & 89.838 & 92.672 \\
\hline Hoteles & 77.272 & 79.295 & 81.390 & 84.978 & 86.946 & 91.065 \\
\hline 5 Estrellas & 16.922 & 17.082 & 17.825 & 20.294 & 21.688 & 24.458 \\
\hline 4 Estrellas & 30.152 & 31.830 & 33.249 & 36.162 & 37.569 & 38.830 \\
\hline 3 Estrellas & 15.908 & 16.034 & 16.263 & 17.431 & 17.482 & 17.539 \\
\hline 2 Estrellas & 8.094 & 8.126 & 8.242 & 6.127 & 6.247 & 7.281 \\
\hline 1 Estrella & 6.196 & 6.223 & 5.811 & 4.964 & 3.960 & 2.957 \\
\hline Otros establecimientos & 6.928 & 6.310 & 5.862 & 4.324 & 2.892 & 1.607 \\
\hline
\end{tabular}

Fuente: ONE, Oficina Nacional de Estadística, 2009. Elaboración propia

De acuerdo con una clasificación elemental de las plazas hoteleras existentes en los diversos polos turísticos de Cuba, se puede distinguir entre una oferta de carácter marcadamente urbano, integrada básicamente por los destinos de La Habana y de Santiago de Cuba, frente a otra oferta prioritariamente de «sol y playa», integrada por los polos turísticos de Varadero, Ciego de Ávila (Cayo Coco y otras playas), Holguín, Cayo Largo del Sur y otros polos menores y diseminados. En el cuadro (según datos de la ONE, 2009), se pone de manifiesto el mayor peso de la oferta hotelera de sol y playa, que, por lo general, duplica a la oferta urbana. En la serie analizada, se comprueba también un ligero aumento porcentual de la oferta en los polos de sol y playa.

Pese a que, por lo general, el turista que llega a la Isla consume tanto productos turísticos urbanos como de sol y playa, el «destino turístico Cuba» presenta una mayor vocación de sol y playa y, a la vez, parece que tiende a especializarse más en ese segmento de mercado, conforme con el progresivo aumento porcentual de uno y otro tipo de oferta hotelera.

Así, una primera conclusión, desprendida de los datos estadísticos y del análisis de las ofertas turísticas cubanas, podría ser que el producto de playas se ve complementado con el producto urbano: la estancia más prolongada en el destino de sol y playa se complementa con algunas excursiones y estancias breves en las principales ciudades del País. Por el contrario, las ciudades insertas en los polos turísticos de sol y playa han quedado al margen del producto turístico, elaborado con mucha frecuencia bajo el formato de complejos turísticos muy especializados -resort-, en espacios acotados para el turista extranjero, poco permeables con el contexto territorial. De ahí el interés por suplir esa carencia y acercar la oferta urbana y cultural de esos polos de sol y playa al potente mercado turístico que pulula por circuitos paralelos y muy próximos. 
Cuadro 3. Cuba. Evolución reciente de las plazas hoteleras por destino principal

\begin{tabular}{|c|c|c|c|c|c|c|}
\hline & 2003 & 2004 & 2005 & 2006 & 2007 & 2008 \\
\hline \multicolumn{7}{|l|}{ Urbano } \\
\hline Establecimientos & 90 & 90 & 87 & 87 & 89 & 94 \\
\hline Habitaciones & 15452 & 15771 & 14795 & 12560 & 13605 & 14270 \\
\hline Plazas & 32072 & 32448 & 30438 & 26420 & 27366 & 30031 \\
\hline \multicolumn{7}{|l|}{ Sol y playa } \\
\hline Establecimientos & 172 & 177 & 179 & 180 & 187 & 190 \\
\hline Habitaciones & 31448 & 31853 & 32259 & 33047 & 34488 & 36078 \\
\hline Plazas & 63421 & 64478 & 63352 & 65693 & 71123 & 74116 \\
\hline \multicolumn{7}{|l|}{ Total } \\
\hline Establecimientos & 262 & 267 & 266 & 267 & 276 & 284 \\
\hline Habitaciones & 46.900 & 47.624 & 47.054 & 45.607 & 48.093 & 50.348 \\
\hline Plazas & 95.493 & 96.926 & 93.790 & 92.113 & 98.489 & 104.147 \\
\hline
\end{tabular}

Fuente: ONE, Oficina Nacional de Estadística, 2009. Elaboración propia

\subsection{La oferta complementaria}

En los destinos turísticos, los componentes menores de la oferta complementaria gozan de un gran atractivo, como son los bares, los restaurantes selectos o, incluso, las discotecas y salas de fiesta. En todos los casos, su cantidad y calidad contribuyen a mejorar el atractivo del destino turístico, siendo, en ocasiones, muy destacado su peso en el momento de la elección del destino final del viaje, o de la duración del mismo.

En general, en las ciudades patrimoniales cubanas, salvo la excepción de La Habana, existe un notable déficit en este sentido. Los destinos urbanos, para ser competitivos y eficientes, deben aunar una oferta variada e internacional de cocina, que cubra desde la más estándar hasta las más selectas. Por sí sola, la oferta de cocina étnica no garantiza el éxito del destino. En ese sentido, resulta elemental atender los gustos de los visitantes, tal como se hace en los hoteles de las grandes cadenas internacionales, con menús estandarizados (desayunos, comidas, cenas) que incluyen algunas variantes de notable atractivo, desde pizzerías (para el segmento más joven o de menor poder adquisitivo) hasta alta cocina internacional.

En La Habana, sobre la base de la cocina tradicional criolla, las ofertas se han ido adaptando paulatinamente a las exigencias de la demanda, mejorando la presentación y la calidad, con notables ingredientes de innovación y diseño, que van tanto en el plato como en el tratamiento del comedor y del ambiente (en 
especial del microclima y de una sonoridad muy modulada). Por el contrario, en las demás ciudades patrimoniales resulta más difícil encontrar la variada oferta que demanda el turista extranjero, abocado, con frecuencia, al producto bastante extendido del restaurante étnico tematizado, con platos demasiado sazonados para los paladares extranjeros, ambientes poco cuidados, donde prima la rusticidad en la decoración y donde, inevitablemente, se come al lado de un grupo musical que dificulta la comunicación y el disfrute pleno del momento.

\section{LA DEMANDA TURÍSTICA}

La oferta hotelera es sólo una de las componentes del mercado turístico, complementada por la demanda de los clientes potenciales. La coherencia mercantil señala que la oferta debe seguir los pasos de la demanda. Esto es, la oferta por sí sola no garantiza el éxito en el negocio turístico. Antes al contrario, son las grandes tendencias en la demanda turística las que deben orientar la estructura (en cantidad y calidad) de la oferta de cada uno de los destinos turísticos. Además, la experiencia demuestra que la demanda es altamente cambiante y se guía por las modas y, claro está, por la inserción en el mercado turístico de nuevos productos emergentes, lo que obliga a un constante esfuerzo de revisión del negocio, en atención a los cambios constantes de la demanda. En esa dirección apuntan las estrategias de diversificación y especialización constantes que ponen en práctica muchos de los destino turísticos maduros o consolidados.

\subsection{Una tendencia creciente del número de viajeros recibidos}

Los datos de la Oficina Nacional de Estadística de Cuba muestran un crecimiento constante de la llegada de visitantes al País, con una evolución espectacular en los años 90, atemperada en el último lustro por los efectos generales de la crisis en los países emisores y, también, por un cierto grado de madurez del producto turístico Cuba y la afección de otros destinos caribeños alternativos.

Cuadro 4. Cuba. Evolución del número de visitantes extranjeros (en miles)

\begin{tabular}{|c|c|c|c|c|c|c|}
\hline año & 1990 & 1995 & 1998 & 2000 & 2001 & 2002 \\
\hline visitantes & 340 & 746 & 1413 & 1774 & 1775 & 1686 \\
\hline año & 2003 & 2004 & 2005 & 2006 & 2007 & 2008 \\
\hline visitantes & 1906 & 2049 & 2319 & 2221 & 2152 & 2348 \\
\hline
\end{tabular}

Fuente: ONE, Oficina Nacional de Estadística, 2009. Elaboración propia 
Si se atiende a las pernoctaciones generadas por ese flujo internacional, se comprueba el aumento general de las mismas, si bien con un desigual ritmo de evolución. Esto es, mientras las pernoctaciones en hoteles de 5 estrellas han mantenido un notable crecimiento, las pernoctaciones en hoteles de 4 estrellas (que constituyen el segmento más voluminoso) han permanecido estancadas entre 2005 y 2007, para repuntar ligeramente en el último año analizado. Mientras el resto de ofertas (todas de menor categoría, incluyendo el hospedaje) muestran un claro estancamiento y, aun, descenso en sus evoluciones recientes.

Cuadro 5. Cuba. Evolución de las pernoctaciones de turismo internacional por categoría de los establecimientos

\begin{tabular}{|l|r|r|r|r|r|r|r|}
\hline $\begin{array}{c}\text { Tipo de } \\
\text { establecimiento }\end{array}$ & \multicolumn{1}{c|}{2002} & \multicolumn{1}{c|}{2003} & \multicolumn{1}{c|}{2004} & \multicolumn{1}{c|}{2005} & \multicolumn{1}{c|}{2006} & \multicolumn{1}{c|}{2007} & \multicolumn{1}{c|}{2008} \\
\hline Hoteles & 9473540 & 11669004 & 13170770 & 14.386 .345 & 14.457 .194 & 14.405 .069 & 15.677 .523 \\
\hline 5 Estrellas & 2384562 & 2624935 & 3329820 & 4.026 .783 & 4.063 .394 & 4.544 .260 & 5.376 .468 \\
\hline 4 Estrellas & 5018249 & 6654639 & 7346875 & 7.760 .526 & 7.800 .436 & 7.632 .446 & 7.974 .023 \\
\hline 3 Estrellas & 1691247 & 1894368 & 1894310 & 1.894 .468 & 1.992 .332 & 1.729 .350 & 1.818 .025 \\
\hline 2 Estrellas & 334548 & 447722 & 550019 & 652.316 & 561.046 & 479.926 & 495.393 \\
\hline 1 Estrella & 44934 & 47340 & 49746 & 52.252 & 39.986 & 19.087 & 13.614 \\
\hline $\begin{array}{l}\text { Otros } \\
\text { establecimientos }\end{array}$ & 281471 & 282467 & 187136 & 185641 & 176446 & 139.162 & 87.062 \\
\hline
\end{tabular}

Fuente: ONE, Oficina Nacional de Estadística, 2009. Elaboración propia

El fenómeno señalado queda más patente si se analiza la evaluación por separado de cada categoría de establecimiento, considerando el año 2005 como el punto de inflexión de las series estadísticas. En el cuadro adjunto se evidencia cómo la tasa de crecimiento interanual de las pernoctaciones ha sido siempre mucho más favorable para los hoteles de mayor categoría, mientras que los establecimientos más modestos han experimentado una evolución más accidentada, con una clara pérdida de clientes en los últimos cuatro años de la serie.

Se concluye, por tanto, que es el segmento de visitantes de mayor poder adquisitivo el que mantiene mejor el negocio turístico en Cuba. Cabe recordar que es el turista urbano el que presenta un perfil de mayor poder adquisitivo, y mayor nivel cultural, por tanto, es más exigente y menos estacional, y, además, desarrolla su ocio turístico principalmente visitando ciudades de alto valor patrimonial. Mientras el turismo de sol y playa y el de Naturaleza o aventura, con menor poder adquisitivo, busca otras alternativas más económicas o se deja guiar por las ofertas y paquetes de los grandes touroperadores. 
Cuadro 6. Cuba. Evolución relativa de las pernoctaciones por categoría de establecimientos (TCI \%) y periodos significativos

\begin{tabular}{|l|r|r|}
\hline \multicolumn{1}{|c|}{ Tipo de establecimiento } & 2002-2005 & 2005-2008 \\
\hline Hoteles & 11,0 & 2,0 \\
\hline 5 Estrellas & 14,0 & 7,3 \\
\hline 4 Estrellas & 11,5 & 0,6 \\
\hline 3 Estrellas & 2,9 & $-2,3$ \\
\hline 2 Estrellas & 18,2 & $-3,1$ \\
\hline 1 Estrella & 3,8 & $-23,6$ \\
\hline Otros establecimientos & $-9,9$ & $-16,2$ \\
\hline
\end{tabular}

Fuente: ONE, Oficina Nacional de Estadística, 2009. Elaboración propia

La llegada de visitas internacionales se concentra en el semestre invernal del Hemisferio Norte, de donde procede la mayor parte de los turistas. El gráfico anual muestra un notable equilibrio mensual, que habla de una cierta desestacionalización de las llegadas. Indudablemente, se trata de visitantes que buscan el buen tiempo entre la oferta de sus destinos, pero el perfil del visitante durante el invierno se aleja sensiblemente del turista estival, más orientado al consumo de productos muy específicos de sol y playa.

Figura 1

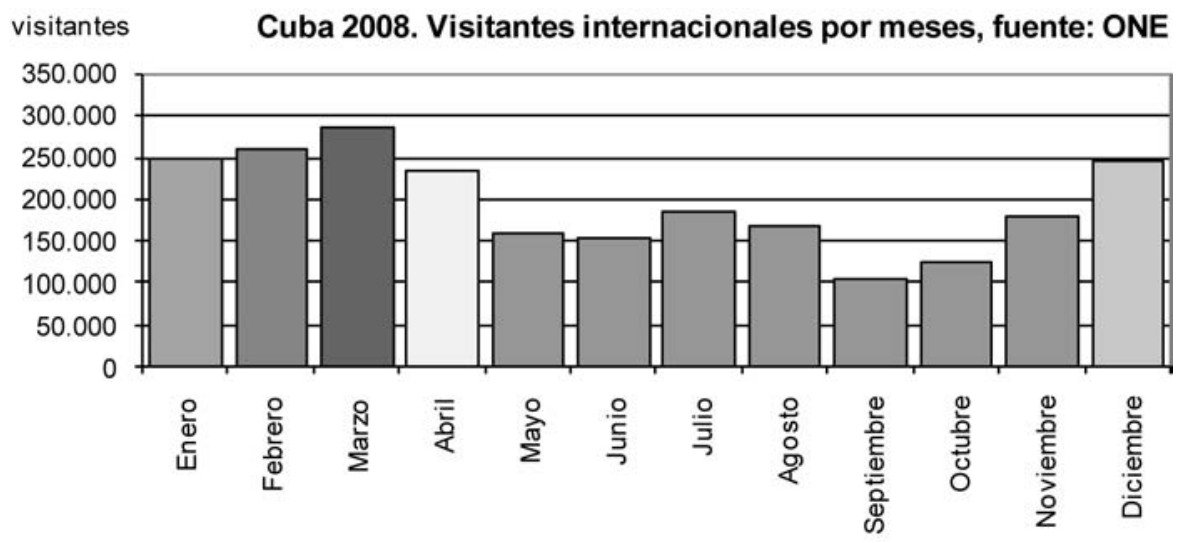

Se dibuja así el perfil de un turista que puede viajar en diferentes momentos del año, y no sólo durante el verano, que tiene un elevado poder adquisitivo, un buen nivel cultural y que es, a la vez, muy exigente en cuanto a la calidad de los servicios contratados. Tales son los rasgos básicos del turista 
urbano, consumidor de productos culturales de calidad, entre los que destaca el patrimonio arquitectónico, las ciudades históricas y el patrimonio intangible. Esto es, el mercado potencial para las ciudades patrimoniales cubanas ya frecuenta la Isla y sus principales destinos turísticos, lo que constituye una enorme ventaja comparativa para el desarrollo de una oferta turística patrimonial de calidad.

\subsection{Los mercados emisores}

En el conjunto de visitantes se observa el destacado peso de los canadienses, que suponían aproximadamente el 35\% de los llegados a Cuba en 2008. Se trata, por consiguiente, de unos turistas fidelizados, que repiten año tras año en busca, sobre todo, del producto de sol y playa.

Analizados los visitantes por grandes grupos de países emisores se observa cómo, mientras los países europeos y el resto del Mundo han ido perdiendo cuota como origen de los visitantes, Canadá ha ido ganando peso hasta convertirse en el principal sostén del moderado crecimiento de los turistas en Cuba. Sin duda, el clima y las playas, junto a una cierta cercanía y un interesante cambio de divisas, constituyen la base de la gran atracción por el destino. No obstante, también otros aspectos contribuyen a esa fidelización, entre los que destaca la cultura cubana en general, el patrimonio etnológico, la seguridad del destino, la calidad de los productos frente a otros competidores y, claro está, la posibilidad de interactuar con los autóctonos.

Tales aspectos culturales se hallan también en la base del atractivo que suscita el destino Cuba entre los países emisores europeos, afectados, no obstante, por la mayor distancia, el paulatino encarecimiento del viaje y los efectos de la crisis económica, que ha llevado a los turistas a optar por otros destinos más accesibles.

\subsection{Tipología de la estancia}

La estancia media de los viajeros en cada destino es también indicador válido del perfil de los turistas. Por lo general, el equipamiento hotelero específico de sol y playa registra unas estancias más largas que las que caracterizan al turismo urbano o cultural. La estancia promedio es bastante elevada, rondando los 5 días por turista internacional, cifra característica de un destino de sol y playa. En ese sentido, se observa cómo las estancias más prolongadas se dan en apartamentos y en casas, seguidas por las estancias en hoteles, donde las estancias más largas se dan, por este orden, en los de 4 estrellas, de 5 estrellas y de 3 estrellas. 
Cuadro 7. Cuba. Evolución del número de visitantes por países

\begin{tabular}{|lr|r|r|r|r|r|r|}
\cline { 2 - 8 } \multicolumn{1}{c|}{} & \multicolumn{1}{c|}{2002} & \multicolumn{1}{c|}{2003} & \multicolumn{1}{c|}{2004} & \multicolumn{1}{c|}{2005} & \multicolumn{1}{c}{2006} & \multicolumn{1}{c}{2007} & \multicolumn{1}{c|}{2008} \\
\hline Total & 1686162 & 1905682 & 2048572 & 2.319 .334 & 2.220 .567 & 2.152 .221 & 2.348 .340 \\
\hline $\begin{array}{l}\text { Principales } \\
\text { emisores }\end{array}$ & 1405832 & 1604458 & 1776899 & 1990150 & 1863571 & 1788042 & 1.941 .807 \\
\hline Canadá & 348468 & 452438 & 563371 & 602377 & 604263 & 660384 & 818.246 \\
\hline Inglaterra & 103741 & 120866 & 161189 & 199399 & 211075 & 208122 & 193.932 \\
\hline Italia & 147750 & 177627 & 178570 & 169317 & 144249 & 134289 & 126.042 \\
\hline España & 138609 & 127666 & 146236 & 194103 & 185531 & 133149 & 121.166 \\
\hline Alemania & 152662 & 157721 & 143644 & 124527 & 114292 & 103054 & 100.964 \\
\hline Francia & 129907 & 144548 & 119868 & 107518 & 103469 & 92304 & 90.731 \\
\hline México & 87589 & 88787 & 79752 & 89154 & 97984 & 92120 & 84.052 \\
\hline $\begin{array}{l}\text { Estados } \\
\text { Unidos }\end{array}$ & 77646 & 84529 & 49856 & 37233 & 36808 & 40521 & 41.904 \\
\hline Argentina & 9389 & 13929 & 23460 & 24922 & 30383 & 37922 & 47.405 \\
\hline Holanda & 27437 & 29451 & 32983 & 37818 & 35871 & 33605 & 33.548 \\
\hline Venezuela & 10977 & 15228 & 86258 & 185157 & 83832 & 33593 & 31.931 \\
\hline Rusia & 10653 & 12610 & 17457 & 20711 & 27861 & 29077 & 40.621 \\
\hline
\end{tabular}

Fuente: ONE, Oficina Nacional de Estadística, 2009. Elaboración propia

La media de 5 días por visitante es característica del perfil del turista, mientras las otras modalidades de visita registran siempre medias de estancia mucho más bajas, tanto los excursionistas (conforme con su propia definición) como las visitas por negocios y por motivos profesionales. En ese sentido, resultan elocuentes las cifras de estancia media recogidas en los hoteles de La Habana Vieja en el mismo periodo cronológico: el descenso desde casi 3 días por turista hasta menos de un día por turista es indicador del desarrollo experimentado por el producto turístico de sol y playa en detrimento del turismo urbano y patrimonial en Cuba.

El fenómeno se hace más evidente al comparar la estancia media en los hoteles de La Habana Vieja (gestionados por la Oficina del Historiador de La Habana) y la estancia media en los hoteles de Plaza de la Revolución, ámbito de la Ciudad de La Habana, donde han radicado sus establecimientos las cadenas hoteleras internacionales: la reducción del periodo de estancia también es manifiesta, si bien la estancia promedio es más elevada que la registrada en La Habana Vieja, sin duda por los efectos del paquete integrado La Habana+Varadero o La Habana+otros destinos de sol y playa. 
Cuadro 8. Cuba. Estancia media turistas internacionales por tipo de alojamientos (días)

\begin{tabular}{|c|c|c|c|c|c|c|}
\hline & 2003 & 2004 & 2005 & 2006 & 2007 & 2008 \\
\hline Total & 4,9 & 4,9 & 5,0 & 5,2 & 5,0 & 5,0 \\
\hline Hoteles y otros establecimientos & 5,0 & 4,9 & 5,0 & 5,2 & 5,1 & 5,0 \\
\hline Hoteles & 5,1 & 5,0 & 5,1 & 5,3 & 5,1 & 5,0 \\
\hline 5 Estrellas & 4,4 & 4,7 & 4,9 & 4,9 & 5,0 & 5,1 \\
\hline 4 Estrellas & 6,2 & 6,0 & 6,3 & 6,3 & 5,8 & 5,7 \\
\hline 3 Estrellas & 3,7 & 3,9 & 3,6 & 4,1 & 4,1 & 4,2 \\
\hline 2 Estrellas & 4,2 & 2,8 & 3,2 & 3,3 & 2,6 & 2,4 \\
\hline 1 Estrella & 2,3 & 1,9 & 1,4 & 1,9 & 1,5 & 1,4 \\
\hline Otros establecimientos & 2,7 & 1,9 & 2,1 & 2,9 & 4,3 & 3,2 \\
\hline Moteles & 1,7 & 0,2 & 0,1 & 0,1 & 1,0 & 1,0 \\
\hline Hoteles-Apartamentos * & 8,4 & 9,3 & 10,6 & 15,2 & 30,8 & 14,3 \\
\hline Hostal & 1,8 & 2,0 & 2,5 & 2,6 & 2,5 & 2,5 \\
\hline $\begin{array}{l}\text { Medios de alojamiento } \\
\text { complementarios }\end{array}$ & 4,0 & 4,6 & 4,7 & 5,0 & 3,7 & 4,2 \\
\hline Bases de campismo & 2,4 & 2,6 & 2,2 & 2,2 & 2,0 & 1,9 \\
\hline $\begin{array}{l}\text { Otros establecimientos } \\
\text { complementarios }\end{array}$ & 4,1 & 4,7 & 4,9 & 5,3 & 3,9 & 4,4 \\
\hline Casas y cabañas ** & 7,7 & 6,1 & 6,7 & 8,1 & 10,7 & 17,6 \\
\hline Campamentos & 3,4 & 3,3 & 3,1 & 2,1 & 1,4 & 1,4 \\
\hline Otros & 4,0 & 4,7 & 4,8 & 5,3 & 3,7 & 4,2 \\
\hline De ello: Villas turísticas & 4,2 & 4,7 & 4,8 & 5,6 & 3,8 & 4,3 \\
\hline
\end{tabular}

Fuente: ONE, Oficina Nacional de Estadística, 2009. Elaboración propia

Cuadro 9. La Habana Vieja. Indicadores perfil del turista

\begin{tabular}{|l|r|r|r|r|r|r|}
\cline { 2 - 7 } \multicolumn{1}{c|}{} & \multicolumn{1}{c|}{2003} & \multicolumn{1}{c|}{2004} & 2005 & 2006 & 2007 & \multicolumn{1}{c|}{2008} \\
\hline $\begin{array}{l}\text { Turistas días } \\
\text { total }\end{array}$ & 484.387 & 533.906 & 543.042 & 566.694 & 607181 & 605.051 \\
\hline $\begin{array}{l}\text { Promedio de } \\
\text { estancia }\end{array}$ & 2,7 & 2,7 & 2,7 & 2,8 & 1,1 & 0,3 \\
\hline $\begin{array}{l}\text { Ingresos } \\
\text { totales } \\
\text { (dólares) }\end{array}$ & $31.379,2$ & $102.093,1$ & $106.655,6$ & $105.957,9$ & $126.738,1$ & $151.109,4$ \\
\hline
\end{tabular}

Fuente: ONE, Oficina Nacional de Estadística, 2009. Elaboración propia 
Cuadro 10. Plaza de la Revolución (Ciudad de La Habana). Indicadores perfil del turista

\begin{tabular}{|l|r|r|r|r|r|r|}
\cline { 2 - 7 } \multicolumn{1}{c|}{} & \multicolumn{1}{c|}{2003} & \multicolumn{1}{c|}{2004} & \multicolumn{1}{c|}{2005} & \multicolumn{1}{c|}{2006} & \multicolumn{1}{c|}{2007} & \multicolumn{1}{c|}{2008} \\
\hline Turistas días total & 902.957 & 905.164 & 933.016 & 947.223 & 941.539 & 353.138 \\
\hline $\begin{array}{l}\text { Promedio de } \\
\text { estancia }\end{array}$ & 3,1 & 2,9 & 3,0 & 2,9 & 2,8 & 2,7 \\
\hline $\begin{array}{l}\text { Ingresos totales } \\
\text { (miles dólares) }\end{array}$ & 149,4 & 193,5 & 216,7 & 197,6 & 209,0 & 214,7 \\
\hline
\end{tabular}

Fuente: ONE, Oficina Nacional de Estadística, 2009. Elaboración propia

Cuadro 11. Cuba. Tipología de los turistas (miles)

\begin{tabular}{|l|r|r|r|r|r|r|r|}
\hline $\begin{array}{c}\text { Llegadas } \\
\text { internacionales }\end{array}$ & 2002 & 2003 & 2004 & 2005 & 2006 & 2007 & 2008 \\
\hline Visitantes & 1686 & 1906 & 2049 & 2.319 & 2.221 & 2.152 & 2.348 \\
\hline Turistas & 1656 & 1847 & 2.017 & 2.261 & 2.150 & 2.119 & 2.316 \\
\hline Excursionistas & 30 & 59 & 32 & 58 & 71 & 33 & 32 \\
\hline $\begin{array}{l}\text { Pasajeros en } \\
\text { crucero }\end{array}$ & 6 & 20 & 5 & 17 & 30 & 7 & 5 \\
\hline
\end{tabular}

Fuente: ONE, Oficina Nacional de Estadística, 2009. Elaboración propia

Cuadro 12. Cuba. Llegas de turistas por motivo de visita

\begin{tabular}{|l|c|c|c|c|c|c|c|}
\cline { 2 - 8 } \multicolumn{1}{c|}{} & 2002 & 2003 & 2004 & 2005 & 2006 & 2007 & 2008 \\
\hline $\begin{array}{l}\text { Vacaciones, } \\
\text { ocio y recreo }\end{array}$ & 1560 & 1736 & 1830 & 1.982 & 1.931 & 1.989 & 2.190 \\
\hline $\begin{array}{l}\text { Negocios } \\
\begin{array}{l}\text { y motivos } \\
\text { profesionales }\end{array}\end{array}$ & 13 & 12 & 11 & 12 & 13 & 12 & 12 \\
\hline Otros & 83 & 99 & 176 & 267 & 206 & 118 & 114 \\
\hline
\end{tabular}

Fuente: ONE, Oficina Nacional de Estadística, 2009. Elaboración propia

De la tipología puede concluirse que las vacaciones de sol y playa constituyen el motivo principal del viaje a Cuba y, también, la demanda que genera mayor ocupación hotelera (periodos más largos de estancia). Esto es, en el perfil turístico del producto Cuba la oferta de sol y playa aparece destacada. Las buenas condiciones climáticas del País se aprovechan por los turistas durante las vacaciones de Navidad y en otros periodos festivos del invierno y la primavera, momentos en los que, evidentemente, el objetivo sustancial del viajero es el disfrute del buen clima. Las motivaciones estrictamente culturales se reparten por todo el año, en todos los casos con un periodo de estancia limitado, acotado por la propia naturaleza de un desplazamiento considerablemente alejado de los principales países emisores. 


\subsection{El patrimonio como motor de la demanda en las perspectivas de futuro}

Los escenarios futuros de la actividad turística en el mundo desarrollado permiten ser optimistas en lo que respecta a esta actividad y su desarrollo en las ciudades patrimoniales de Cuba. Desde el punto de vista de la oferta, se comprueba cómo todas las ciudades se están dotando de todo un sistema integrado física y políticamente para hacer frente a ese reto de futuro. Las estrategias claves ya están en marcha: identificación y puesta en valor de sus recursos potenciales, mejora de la oferta hotelera y ajuste a las demandas, mejora de las infraestructuras generales y de los equipamientos específicos para el turismo, desarrollo de una variada oferta complementaria (ocio, compras, cultura, descanso).

A principios de siglo, ante el proceso de estancamiento de la demanda con destino a Cuba y el proceso de maduración del producto cubano, el Instituto Nacional de Investigaciones Económicas del Ministerio de Economía y Planificación de Cuba elaboró un análisis prospectivo de las demandas de turismo internacional a Cuba para el horizonte 2003-2010 (MEP/INIE, 2004). La encuesta se apoyaba en diversas técnicas prospectivas, como el método de análisis estructural o MICMAC, que permitía identificar las principales variables influyentes y dependientes en la evolución del sistema turístico cubano, el método MACTOR para reconocer a los principales actores nacionales e internacionales con influencia en el sistema turístico cubano, el método Escenarios para interpretar los escenarios tendenciales de las variables consideradas y el método DELPHI de consulta a expertos sobre la valoración de las diversas variables, las posibles interacciones entre ellas y sus evoluciones tendenciales.

Como se observa en los cuadros que sintetizan la valoración de las variables por los expertos, la cultura y el patrimonio cubano alcanzan un destacado peso en las estimaciones de demanda. De un total de 436 respuestas, esa variable interna se colocó en cuarto lugar por importancia, con un peso del 81\%, sólo por detrás de otras variables fundamentales para ése y cualquier destino turístico, como son las infraestructuras de transporte, la imagen proyectada y la calidad del producto. Esto es, descontadas esas variables de carácter general, el patrimonio y la cultura cubana alcanzaban el primer puesto entre las consideradas estrictamente locales, muy por encima de otras específicamente vinculadas con el negocio turístico. Las mismas 436 respuestas daban el primer puesto en la valoración de las variables externas a las nuevas tendencias y los nuevos hábitos de consumo, con un peso del 77\%, conceptos en los que se insertan las opciones de turismo cultural, de patrimonio y de experiencia selectiva. 
Cuadro 13. Prospectivas sobre la demanda de turismo a Cuba.

Variables internas ordenadas por importancia según los expertos (horizonte 2010)

\begin{tabular}{|c|c|c|}
\hline Nombre de la Variable & $\begin{array}{c}\text { peso } \\
\%\end{array}$ & Contenido de la Variable \\
\hline Infraestructuras y transporte & 88 & $\begin{array}{l}\text { Cantidad y calidad de la red } \\
\text { de construcciones básicas de } \\
\text { infraestructuras. }\end{array}$ \\
\hline Calidad en toda la actividad & 85 & $\begin{array}{l}\text { Calidad, estabilidad y variedad de } \\
\text { la oferta. Seguridad sanitaria y de } \\
\text { abastecimientos. }\end{array}$ \\
\hline Imagen del destino y comunicación turística & 85 & $\begin{array}{l}\text { La imagen percibida por los visitantes } \\
\text { que difunden al regreso de su viaje. }\end{array}$ \\
\hline Cultura cubana y patrimonio & 81 & $\begin{array}{l}\text { Cultura y arte cubano vinculados al } \\
\text { producto turístico. }\end{array}$ \\
\hline $\begin{array}{l}\text { Políticas de fomento y desarrollo de la } \\
\text { actividad turística }\end{array}$ & 81 & $\begin{array}{l}\text { Potenciar la Planificación y } \\
\text { coordinación del sistema turístico. }\end{array}$ \\
\hline Recursos naturales y atractivos turísticos & 77 & $\begin{array}{l}\text { Clima, paisaje y entorno natural y } \\
\text { geográfico. Manejo de los recursos, } \\
\text { accesibilidad real. }\end{array}$ \\
\hline Equipamiento y oferta turística & 77 & $\begin{array}{l}\text { Oferta turística: hotelera, extrahotelera y } \\
\text { complementaria. Ampliar y flexibilizar }\end{array}$ \\
\hline Capital humano & 77 & $\begin{array}{l}\text { Formación del capital humano en } \\
\text { turismo. Atención profesionalizada al } \\
\text { turismo. }\end{array}$ \\
\hline Productos y destino turístico conformado & 77 & $\begin{array}{l}\text { Diversificación de la oferta sol y playa. } \\
\text { Nuevos nichos: turismo cultural, } \\
\text { educacional, de salud, eventos. }\end{array}$ \\
\hline Políticas de promoción y comercialización & 77 & $\begin{array}{l}\text { Impacto promocional del destino: } \\
\text { imagen transmitida por las campañas de } \\
\text { promoción y publicidad. }\end{array}$ \\
\hline Seguridad del destino & 73 & $\begin{array}{l}\text { Grado de confianza y seguridad } \\
\text { percibido. Libertad de movimiento del } \\
\text { turista. Garantías de seguridad. }\end{array}$ \\
\hline Precio de la oferta turística & 65 & $\begin{array}{l}\text { Precios de toda la oferta turística. } \\
\text { Precios hoteleros competitivos. Agilidad } \\
\text { y flexibilidad. }\end{array}$ \\
\hline Variables económicas en el destino & 65 & $\begin{array}{l}\text { Reformas económicas internas. Apertura } \\
\text { del mercado interno. Estabilidad de los } \\
\text { suministros energéticos. }\end{array}$ \\
\hline Clima político y social interno & 62 & $\begin{array}{l}\text { Clima y estabilidad sociopolítica } \\
\text { del destino Cuba. Percepción de la } \\
\text { situación política. }\end{array}$ \\
\hline
\end{tabular}

Fuente: INIE, MEP, 2004

Investigaciones geográficas, $n^{\circ}$ 52, pp. 137 - 166 
Cuadro 14. Prospectivas sobre la demanda de turismo a Cuba.

Variables externas ordenadas por importancia según los expertos (horizonte 2010)

\begin{tabular}{|c|c|c|}
\hline Nombre de la Variable & $\begin{array}{c}\text { peso } \\
\%\end{array}$ & Contenido de la Variable \\
\hline $\begin{array}{l}\text { Nuevas tendencias de la demanda y } \\
\text { factores que influyen sobre los mercados } \\
\text { turísticos }\end{array}$ & 77 & $\begin{array}{l}\text { Profundos cambios en los hábitos de } \\
\text { consumo de los turistas. Creciente } \\
\text { demanda de otras actividades y } \\
\text { servicios con calidad ambiental. } \\
\text { Mejoras tecnológicas en la industria } \\
\text { turística. }\end{array}$ \\
\hline Competencia y estrategias & 77 & $\begin{array}{l}\text { Desarrollo acelerado de la } \\
\text { competencia en la región del Caribe y } \\
\text { Centroamérica. } \\
\text { Guerra de precios. Diferenciación por } \\
\text { nuevos atributos que hagan al destino } \\
\text { más competitivo. }\end{array}$ \\
\hline Variables económicas en los países emisores & 73 & $\begin{array}{l}\text { Situación económica y del nivel de renta } \\
\text { de los países emisores. Precios relativos } \\
\text { entre emisores y destino. Paridad } \\
\text { monetaria (tasa cambiarias). Volatilidad } \\
\text { de los mercados emisores. }\end{array}$ \\
\hline Relaciones Cuba-EE.UU. & 65 & $\begin{array}{l}\text { Cambios en la inmovilidad de la política } \\
\text { exterior del gobierno de EE.UU. hacia } \\
\text { Cuba condicionaría un nuevo escenario } \\
\text { para el comportamiento de la actividad } \\
\text { turística. Apertura del mercado } \\
\text { americano. }\end{array}$ \\
\hline Contingencias, clima político externo & 62 & $\begin{array}{l}\text { Crisis política a escala mundial (actos } \\
\text { de terrorismo y guerras). Inestabilidad } \\
\text { política mundial. } \\
\text { Conflictos internacionales. Riesgos } \\
\text { de epidemias, catástrofes u otras } \\
\text { contingencias en regiones turísticas. }\end{array}$ \\
\hline $\begin{array}{l}\text { Efectos de la globalización en los canales de } \\
\text { distribución }\end{array}$ & 62 & $\begin{array}{l}\text { Necesidad de trazar nuevas líneas de } \\
\text { posicionamiento de los productos } \\
\text { turísticos y acciones que aprovechen } \\
\text { las ventajas y contrarresten el impacto } \\
\text { globalizador en la actividad turística. }\end{array}$ \\
\hline Comunicación aérea y marítima & 58 & $\begin{array}{l}\text { Cambios en las estructuras de mercado } \\
\text { del transporte aéreo por la irrupción de } \\
\text { las compañías de bajo costo. Ausencia } \\
\text { de nuestra línea bandera en países } \\
\text { emisores importantes y dominio de } \\
\text { los espacios aéreos por aerolíneas más } \\
\text { poderosas (o de bajo costo) y por vuelos } \\
\text { charter. }\end{array}$ \\
\hline
\end{tabular}

Fuente: INIE, MEP, 2004 


\section{CONCLUSIONES}

Del análisis de las demandas se comprueba cómo el producto turístico Cuba no es ajeno, en absoluto, al producto de sol y playa, motivación fundamental para los viajeros. Tal demanda aparece concentrada en el invierno del hemisferio Norte, de donde proceden la mayor parte de los turistas de la Isla. Por ello, no puede olvidarse la mejora constante del producto de sol y playa como principal atractivo del País, que parece demandar una mejora sensible del espacio turístico por excelencia: el frente marítimo, pero sin olvidar el soporte urbano en su conjunto.

Pero tales procesos de cualificación del producto turístico urbano deben realizarse sobre la base de la integración de los procesos en la mejora general de la calidad de vida de los ciudadanos (más infraestructuras y equipamientos) y de la mejora concreta de los escenarios - de vida cotidiana y para el turismo- sobre la base de mantener la autenticidad. Esto es, las estrategias de futuro demandan la mejora del paisaje físico y también del paisaje social.

Atender a ese aspecto social comporta uno de los principales activos de las ciudades patrimoniales cubanas -la pluriculturalidad étnica-, que debe servir como fundamento para el deseado proceso de potenciación de la imagen turística de las ciudades patrimoniales cubanas, siempre sobre bases de autenticidad. Como va dicho, la especialización y diferenciación tanto del producto turístico como de la oferta complementaria son la clave para acceder a mayores segmentos del mercado turístico y, al tiempo, para evitar la creciente competencia de otros destinos próximos -caribeños-, que si bien plantean una seria competencia en cuanto a los productos de sol y la playa, por el contrario se manifiestan como destinos cultural y patrimonialmente vacíos.

Además del frente marítimo, es preciso potenciar las otras modalidades de turismo con impronta en las ciudades patrimoniales, que presentan claras oportunidades de desarrollo para el turismo urbano, cultural y de ocio. Los mercados no están muy lejos, ya que esta orientación debe atender, en primer lugar, al turista actualmente acantonado en los polos y resort playeros. En ese sentido, las ciudades patrimoniales cubanas deben seguir desarrollando estrategias de potenciación de prácticas turísticas asociadas a las propias funciones urbanas que ya poseen, ya sean relacionadas con el propio patrimonio, como con el ocio, con los negocios, el comercio y la oferta de servicios personales especializados.

En otro orden de cosas, muchas de las ciudades patrimoniales ya tienen en marcha una clara estrategia de celebración de festivales y eventos con gran atractivo, con programas y proyectos ajustados a la realidad del mercado y, por ello, económica, ecológica y socialmente sostenibles.

La oferta complementaria más cualificada -exposiciones, museos, archivosprecisa una especial atención en tanto presentan un doble objetivo. Por un lado, 
han de servir para cualificar la oferta de turismo cultural, pero, a la vez, han de ser cauce de mejora de la comprensión ciudadana de que el negocio turístico es cosa de todos. La participación e implicación (social, cultural y económica) de toda la población de las ciudades patrimoniales parece estrategia fundamental par el éxito del proceso.

El interés por el patrimonio es fuente de nuevos productos emergentes para el mercado turístico. El turismo cultural consume patrimonio físico y social. Por ello, las estrategias de recuperación y puesta en valor deben atender de forma equilibrada a ambos aspectos. La «marca ciudad patrimonial» debe constituir la idea fuerza que cale realmente de arriba hacia abajo en todos los planes, proyectos y programas, desde la recuperación de los diferentes escenarios históricos, hasta la recuperación de los actuales escenarios donde se desenvuelve hoy el patrimonio vivo.

También la oferta complementaria debe imbuirse de ese concepto a la vez internacionalizado y diferenciado, desde los hoteles hasta la gastronomía. La mejora de la oferta complementaria pasa también por integrar ocio y turismo, ocio y disfrute de patrimonio, con propuestas culturales, educativas, formativas y deportivas que, a la vez que satisfagan las necesidades de la población autóctona, favorezcan el atractivo de la ciudad patrimonial, que debe ser histórica, pero también, y ello es fundamental, debe ser ciudad moderna, eficaz y que funcione. En ese sentido, la actividad comercial y los servicios deben recrear nuevos escenarios más ajustados a las demandas de la ciudadanía en general y de los turistas del siglo XXI.

En definitiva, no debe olvidarse que el turismo es, por naturaleza, una actividad transversal, proyecto común de toda una ciudad, de sus gobernantes, de sus agentes sociales y de sus vecinos. La integración en un completo sistema urbano eficaz resulta clave para garantizar la sostenibilidad y competitividad del «producto turístico ciudad patrimonial»: medio ambiente, cultura y patrimonio, transportes, abastecimientos, tratamiento de residuos, oferta complementaria y armonía social.

\section{BIBLIOGRAFÍA}

Ayala Castro, H., Notas sobre turismo y economía en Cuba en los 90, Valencia, Universidad de Valencia, 1995, 21 pp.

BARONI BASSONI, S., Hacia una cultura del territorio, Centro Regionale de Intervento per la Cooperazione y Grupo para el Desarrollo Integral de la Capital, Ciudad de La Habana, 2003, 143 pp.

Brismat Delgado, N. M., «Integración patrimonio-turismo en el centro histórico de la Ciudad de La Habana: retos y utopías», Ciudad y cambio social en los 90, Universidad de La Habana, 2000, pp. 54-67. 
Calderón García, H., Gil Saura, I., Pons García, R.C., «El posicionamiento de Cuba como destino turístico en la Comunidad Valenciana», Papers de Turismo, no 25 (1999), pp. 102-127.

Cuevo Masoné, H., «40 años de la planificación física en Cuba. Logros, experiencias y retos», Planificación física-Cuba, n 1, 2001, pp. 3-11.

De la Calle Varquero, M., La ciudad histórica como destino turístico, Ariel, Barcelona, 2002, 302 pp.

ECHARRI, M., Diagnóstico de la actividad turística en el centro histórico de La Habana, tesis en opción al título de Master en Geografía, Medio Ambiente y Ordenamiento Territorial en la Universidad de La Habana, año 2001, inédita.

Echarri, M., Salinas, E., «Turismo de Patrimonio en el Centro Histórico de La Habana (Cuba)», Paisaje, Ordenamiento Territorial y Turismo Sostenible, Universidad degli Studi di Génova, Génova, 2003, pp. 69-80.

Figueras, M. A., «El turismo internacional y la formación de cluster productivos en la economía cubana», XXII Congreso Asociación estudios Latino Americanos, Washington D.C., septiembre 2001, 18 pp.

González Arencibia, M., «Retos y oportunidades de la globalización para la economía cubana», Simposio Internacional del Proyecto de Investigación «Reforma Económica y Cambio Social en América Latina y el Caribe»: cuatro casos de estudio, Colombia, Costa Rica, Cuba, México, Pontificia Universidad Javeriana de Cali, 27-29 de octubre de 1999, publicada en CD-ROM y páginas Web de INTERNET de la Universidad Javeriana, http://www.puj.edu.co y de la Fundación Ford, http://www.fordfound.org.

Guerra, CH. Pardo, V., (editores), Manejo y gestión de centros históricos. Conferencias de los Encuentros internacionales II y III La Habana Vieja, 2003 y 2004, ed. Boloña, La Habana, 2006, 348 pp.

Hernández, R., Ariet, M., Turismo estructura general, 1995, memoria inédita contemplada en el Plan Maestro, Oficina del Historiador de La Habana.

Herrero Prieto, L. C., (coord.), Turismo cultural: el patrimonio histórico como fuente de riqueza, Fundación del Patrimonio Histórico de Castilla y León, Valladolid, 2000, 383 pp.

ICOMOS, 1976, Carta de Turismo Cultural.

Instituto Nacional de Investigaciones Económicas, Ministerio de Economía y Planificación de Cuba elaboró un análisis prospectivo de las demandas de turismo internacional a Cuba (MEP/INIE, 2003-2004), inédito.

Lanza Macías, E., «Cinco capítulos por la imagen urbana y la ciudad», en Rev. Planificación física-Cuba, La Habana, 1989, 37 pp.

Leal Spengler, E., La Habana, ciudad antigua, Editorial Letras Cubanas, La Habana, 1988, $123 \mathrm{pp}$. 
MenÉndez García, M., «La Habana Vieja: ambientes en transformación», Planificación física-Cuba, no 7, 2004, pp. 17-26.

Moreira Ortega, M., «La sostenibilidad económica de los Centros Históricos», Manejo y gestión de centros históricos. Conferencias de los Encuentros internacionales II y III La Habana Vieja, 2003 y 2004, ed. Boloña, La Habana, 2006, pp. 165-173.

Mutal, S., «El futuro de las ciudades históricas», Manejo y gestión de centros históricos. Conferencias de los Encuentros internacionales II y III La Habana Vieja, 2003 y 2004, ed. Boloña, La Habana, 2006, pp. 35-70.

Oficina Nacional de Estadística, Anuarios de Cuba, La Habana, ONE, http://www. one.cu/publicaciones

Pogolotti, G., «Cultura, turismo, ciudad», Obras, nº 9, junio, 1999, pp. 8-11.

Ponce Herrero, G. (Dir.), La Habana, de colonia a metrópoli, AECI, Madrid, 2007, 473 pp.

Ponce Herrero, G., «La ciudad moderna en La Habana», Investigaciones Geográficas, $n^{\circ} 42$, enero/abril, 2007, IUG, Universidad de Alicante, Alicante, pp. 129-146.

Ponce Herrero, G., «Planes de reforma urbana para La Habana: la transformación de la ciudad burguesa (1899-1959)» Boletín de la AGE, n45, (3ºuatrimestre de 2007), Asociación de Geógrafos Españoles, Madrid, pp. 327-352.

Ponce Herrero, G., «Crisis, posmodernidad y planificación estratégica en La Habana», Anales de Geografía de la Universidad Complutense, vol. 27, n 2, 2007 , Universidad Complutense Madrid, pp. 133-150.

Ponce Herrero, G., Castro, A, Ortega, I.M., «El turismo como función estratégica», La Habana. De colonia a metrópoli, AECI, Madrid, 2007, pp. 389-414.

Ponce Herrero, G., Labori, M. A., «Contexto y racionalismo en Pinar del Río. Experiencias de planeamiento urbano en Cuba», Ciudad y Territorio. Estudios territoriales, Ministerio de Vivienda, n 126, Madrid, 2000, pp. 727-745.

Ponce Herrero, G., Labori, M. A., «El problema de la vivienda en Cuba: planteamiento urbano y crisis en Pinar del Río», Estudios Geográficos, vol. 62, $n^{\circ} 244$, Consejo Superior de Investigaciones Científicas, CSIC, Instituto de Economía y Geografía, Madrid, 2001, pp. 493-524.

Pons García, R. C., Cuba como destino turístico de "Sol y playa». Imagen y posicionamiento, València, Universitat de València, Departamento de Dirección de Empresas, 2000, 463 pp.

Rodríguez Alomá, P., «Cultura e instrumentos de planificación del desarrollo en los Centros Históricos», Manejo y gestión de centros históricos. Conferencias de los Encuentros internacionales II y III La Habana Vieja, 2003 y 2004, ed. Boloña, La Habana, 2006, pp. 154-164. 
Rodríguez Alomá, P. y Ochoa Alomá, A., Desafío de una utopía. Una estrategia integral para la gestión de salvaguarda de La Habana Vieja, Oficina del historiador de la Ciudad de La Habana. Ciudad City, Ediciones Boloña, Colección Arcos La Habana, 1999, volumen 4.

Rojas Hurtado de Mendoza, R., «Turismo y recuperación urbana: el caso de La Habana», Turismo cultural: el patrimonio histórico como fuente de riqueza, Fundación Patrimonio Histórico de Castilla y León, Valladolid, 2000, pp. 155-204.

Salinas, E., Echarri, M., «Turismo y desarrollo sostenible: el caso del centro histórico de La Habana -Cuba-», Pasos, vol. 3, nº 1, 2005, pp. 171-188.

Salinas, E., Osorio, J.A., «Turismo y sustentabilidad: de la teoría a la práctica en Cuba», Cuadernos de Turismo, no 17, Universidad de Murcia, 2006, pp. 201-221.

Salinas, E., Mundett, LL., «El turismo en Cuba. Un análisis geográfico», El turismo en Cuba, Geographicalia, (no seriada), Universidad de Zaragoza, 2000, pp. 53-66.

Serrano Raffo, F., Del Risco Y., Estévez Pazó, R., «Planeamiento del turismo y geografía: Desarrollo en Cuba en los últimos 40 años», Geographicalia, n ${ }^{\circ} 1$, 2000, pp. 151-160. 